\title{
Effect of 1-year smoking cessation on airway inflammation in COPD and asymptomatic smokers
}

\author{
B.W.M. Willemse*,\#, N.H.T. ten Hacken\#, B. Rutgers*, I.G.A.T. Lesman-Leegte ${ }^{\#}$, \\ D.S. Postma ${ }^{\#}$ and W. Timens*
}

ABSTRACT: Smoking cessation is the only treatment in patients with chronic obstructive pulmonary disease (COPD) effective in slowing down disease progression. Its effect on airway inflammation in COPD is unknown, although cross-sectional studies suggest ongoing inflammation in ex-smokers.

In order to elucidate the effect of smoking cessation on airway inflammation, 28 smokers with COPD (mean age: 55 yrs; forced expiratory volume in one second: $71 \%$ predicted) and 25 asymptomatic smokers with normal lung function (aged 50 yrs) were included in a 1-yr smoking cessation programme. Effects of smoking cessation on airway inflammation were investigated in bronchial biopsies (baseline, 12 months) and sputum samples (baseline, 2, 6 and 12 months).

In the 12 candidates with COPD who successfully ceased smoking, airway inflammation persisted in bronchial biopsies, while the number of sputum neutrophils, lymphocytes, interleukin (IL)-8 and eosinophilic-cationic-protein levels significantly increased at 12 months. In the 16 asymptomatic smokers who successfully quitted, inflammation significantly reduced (i.e. number of sputum macrophages, percentage of eosinophils and IL-8 levels) or did not change.

The current authors suggest that the observed persistent airway inflammation in patients with chronic obstructive pulmonary disease is related to repair of tissue damage in the airways. It remains to be elucidated whether this reflects a beneficial or detrimental effect.

KEYWORDS: Airway inflammation, asymptomatic smokers, bronchial biopsies, chronic obstructive pulmonary disease, induced sputum, smoking cessation

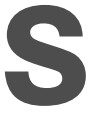
moking is the main risk factor in the development of chronic obstructive pulmonary disease (COPD), which is characterised by chronic respiratory symptoms and airway obstruction. Pathological changes in the lungs include: increased inflammation, fibrosis of the airway wall, and destruction of alveolar attachments. COPD is one of the most important causes of death and its prevalence is still increasing [1]. Until now, smoking cessation is the only treatment effective in slowing down the accelerated decline in forced expiratory volume in one second (FEV1) and thus progression of the disease. However, the exact role of smoking cessation on airway inflammation in COPD is still unknown [2].

A few cross-sectional studies have investigated effects of smoking cessation by comparing smokers and ex-smokers with COPD. Airway

For editorial comments see page 764 . inflammation in bronchial biopsies and sputum did not differ between smokers and ex-smokers, except for some cytokines (interleukin (IL)- 8, IL6, soluble tumour necrosis factor-receptor (sTNFR)75 and sTNF-R55) [3-8]. Furthermore, RUTGERS et al. [9] showed that airway inflammation was more extensive in ex-smokers with COPD than in healthy ex-smokers. Together, these cross-sectional studies suggest that there is ongoing inflammation in COPD after smoking cessation. However, longitudinal studies are not available to confirm these cross-sectional findings.

In asymptomatic smokers, longitudinal studies investigating sputum and bronchoalveolar lavage (BAL) fluid, showed that airway inflammation decreased after smoking cessation, e.g. the number of macrophages and neutrophils [10-16]. This suggests that the inflammatory changes in the airways due to smoking are reversible in smokers without COPD. It remains to be established what exactly occurs in the airway walls and lung parenchyma after smoking cessation.

\section{AFFILIATIONS}

*Dept of Pathology, and

"Dept of Pulmonology, University

Medical Centre Groningen, University of Groningen, Groningen, The

Netherlands.

CORRESPONDENCE

W. Timens

University Medical Centre Groningen Dept of Pathology Hanzeplein 1 9713 GZ Groningen The Netherlands Fax: 310503632510 E-mail: w.timens@path.umcg.nl

Received:

September 202004

Accepted after revision:

July 012005

SUPPORT STATEMENT

This project was funded by the Dutch Asthma Foundation (NAF 97.74). 
In order to investigate the effect of smoking cessation on airway inflammation in more detail in smokers with COPD and asymptomatic smokers with normal lung function, the present authors conducted a 1-yr smoking cessation programme. Before, during and after this programme sputum samples were collected from the subjects who successfully quit smoking. In addition, bronchial biopsies were collected before and 1-yr post-smoking cessation.

\section{METHODS}

\section{Subjects}

Subjects were recruited from the pulmonary outpatient clinic of the University Medical Centre Groningen (Groningen, the Netherlands) and by advertisements in local newspapers from September 1998 to December 2000. A total of 63 participants were included in the study. COPD patients were recruited according to the European Respiratory Society (ERS) criteria [17]. At the analysis, the participants were re-categorised according to the more recent American Thoracic Society (ATS)/ERS guidelines [18]. This resulted in three groups of individuals. 1) COPD. This group was categorised, in accordance with the guidelines, as COPD being present when FEV1/forced vital capacity (FVC) post-bronchodilator was $<0.7$. The severity of COPD was based on FEV1 \% predicted post-bronchodilator; e.g. $\geqslant 80 \%$ was mild COPD, $\geqslant 50-80 \%$ was moderate COPD, $\geqslant 30-50 \%$ was severe COPD and $<30 \%$ was very severe COPD. All COPD patients included had chronic respiratory symptoms, i.e. chronic cough and sputum production for at least 3 months for 2 successive yrs. 2) Smokers with chronic bronchitis. Smokers with chronic respiratory symptoms and without airflow limitation, i.e. at risk of developing COPD according to the ATS/ERS criteria were included. 3) Asymptomatic smokers. This group consisted of individuals without chronic respiratory symptoms or airway obstruction, and an FEV1 $\geqslant 85 \%$ pred; they also belong to the at-risk group. Since the authors felt that symptomatic and asymptomatic smokers with normal lung function are different groups of smokers, they were analysed separately.

All participants met the following criteria: aged 45-75 yrs, $>10$ pack-yrs smoking, actual smoking $\geqslant 10$ cigarettes $\cdot$ day $^{-1}$, reversibility to salbutamol $<9 \%$ of the predicted FEV1, no use of inhaled or oral corticosteroids in the previous 6 months, no signs of atopy (no positive skin-prick test for 10 common aeroallergens and serum total immunoglobulin (Ig)E $<200 \mathrm{IU})$, and no respiratory tract infections 1 month prior to the study. During the study patients only used long-acting or short-acting $\beta_{2}$-agonist or ipratropium on a regular basis; inhaled corticosteroids were not used. Only in cases of an exacerbation was a short course of oral corticosteroids allowed.

The local medical ethics committee (University Medical Centre Groningen, Groningen, the Netherlands) approved the study protocol and all subjects gave their written informed consent.

\section{Study design}

Before entering the 1-yr smoking cessation behavioral programme all subjects underwent lung function tests, blood gas analysis, sputum induction and bronchoscopy. Lung function tests and sputum induction were repeated after 2, 6 and 12 months smoking cessation. Bronchoscopy was repeated in patients who successfully quit smoking for $1 \mathrm{yr}$. Before each measurement, subjects were asked not to use long or shortacting $\beta_{2}$-agonists and/or ipratropium at least $12 \mathrm{~h}$ before the test. They did not suffer from a respiratory tract infection nor used oral corticosteroids in the month prior to any of the measurements.

\section{Smoking cessation programme}

The smoking cessation behavioural programme consisted of an intensive group-orientated course for 3 months, followed by five meetings throughout the rest of the year. If necessary, nicotine replacements were administered during the first 3 months; no bupropion or antidepressants were prescribed. Measuring cotinine levels in urine verified smoking cessation before, then 2, 6 and 12 months after smoking cessation. A quitter was defined as someone who refrained from smoking for a minimum of $1 \mathrm{yr}$, with negative cotinine levels (i.e. $<25 \mathrm{ng} \cdot \mathrm{mL}^{-1}$ ) at 2, 6 and 12 months after smoking cessation.

\section{Lung function}

Lung functions (FEV1, FEV1/vital capacity) were measured using dry wedge spirometry (Masterscope, Jaeger, Breda, the Netherlands) according to standardised guidelines [19]. Bronchodilator responsiveness to $400 \mu \mathrm{g}$ salbutamol was measured and post-bronchodilator values were used. Specific airway conductance (sGaw), total lung capacity (TLC) and residual volume (RV) were measured by body plethysmography (Masterscope, Jaeger). Transfer factor of the lung carbon monoxide $(T \mathrm{~L}, \mathrm{CO})$ was assessed by the single breath method using standard equipment (Masterscope, Jaeger).

\section{Sputum induction and processing}

Sputum was induced by inhalation of hypertonic saline and processed as described previously [20]. Sputum samples containing $>80 \%$ of squamous cells were excluded from analysis because of poor cytospin quality. Sputum cytospin slides were stained with May-Grünwald-Giemsa for differential cell counts, which were performed by one observer. Data on reproducibility have previously been reported [21]. IL-8 concentration was measured using ELISA (CLB, Amsterdam, the Netherlands) and eosinophil cationic protein (ECP) concentration was detected using a fluor-enzyme immunoassay (ImmunoCAP ECP, Pharmacia, Uppsala, Sweden).

\section{Bronchoscopy and biopsy processing}

Bronchial biopsies were taken from the subcarinae of the rightmiddle or -lower lobe as described previously [22]. Two biopsies were directly snap-frozen and four biopsies were embedded in paraffin.

From the paraffin biopsies serial sections were cut to a thickness of $4 \mu \mathrm{m}$ and stored at room temperature. Selection of morphological optimal tissue was based on a haematoxylin and eosin (HE) stained slide. Tissue slides were deparaffinised with xylene $(15 \mathrm{~min})$ and dehydrated before staining. Immunohistochemical staining was performed with monoclonal antibodies against: CD3 (A0452; DAKO, Copenhagen, Denmark), CD4 (CD4-368; Novocastra, Newcastle upon Tyne, UK), CD8 (M7103; DAKO), B-cells (CD20, L26, M0755; DAKO), mast cell tryptase (AA1, M7052; DAKO), neutrophil elastase (NP57, M0752; DAKO), macrophages (CD68, M0814; DAKO), secreted form of eosinophilic cationic protein EG2 (Pharmacia Diagnostics, Sweden), granzyme B (Mon7029; Monosan, the 
Netherlands) and T-cell intracellular antigen-1 (Tia-1; PN IM 2550; Immunotech, France). Negative controls were obtained by omission of the primary antibody. Slides were pre-treated with 1mM EDTA buffer pH8 (CD4, CD8), $10 \mathrm{mM}$ citrate buffer pH6 (granzyme B) and $0.1 \mathrm{mM}$ tris-HCL buffer pH9.0 (CD20) in the microwave for 8,8 or 30 min respectively or with $1 \%$ protease for $30 \mathrm{~min}$ at room temperature (CD68, NP57, AA1, EG2). CD3 slides were incubated overnight at $80^{\circ} \mathrm{C}$ with trisHCL buffer $\mathrm{pH} 9$. Slides stained with Tia-1 were not pretreated. All staining except CD4 was performed automatically using the Dako Autostainer (DAKO). CD4 was done manually. Pre-incubation with $0.3 \%$ hydrogen peroxide was used to block endogenous peroxidase.

The dilutions used were: CD3 1:100; CD4 1:25; CD8 1:100; CD68 1:50; EG2 1:200; NE 1:200; AA1 1:100; CD20 1:400; granzyme B 1:5; Tia-1 1:500. The LSAB+(K0690, DAKO) detection system was used except for CD4 where the Envision detection system was used (K5007; DAKO). Either the 3-Amino-9-Ethyl Carbazole (AEC; K3469; DAKO) or for CD4, Nova Red (SK4800; Vector, USA) were used as a chromogen (substrate) giving a reddish-brown reaction product. Haematoxylin was used as a counterstain.

The frozen biopsies were used to investigate expression of vascular adhesion molecules. Serial sections were cut with a thickness of $4 \mu \mathrm{m}$ and stored at $-20^{\circ} \mathrm{C}$ until used. Selection of morphological optimal tissue was based on HE stained slides. Before immunostaining the sections were dried and fixed in acetone for $10 \mathrm{~min}$ and washed in PBS. Double immunostaining was performed to visualise all vessels using a monoclonal antibody against CD31 (MON1142; Monosan), which is present on all endothelial cells in combination with monoclonal antibodies against the adhesion molecules: intercellular adhesion molecule (ICAM)-1 (anti-CD54; Novocastra), vascular cell adhesion molecule (VCAM; CD106; Genzyme, Cambridge, MA, USA), P-selectin (CD62P; BD Biosciences, San Jose, CA, USA), and E-selectin (CD62E; Genzyme). The concentrations used were: ICAM 1:800, VCAM 1:1000, P-selectin 1:2500 and Eselectin 1:700. Labelling of anti-CD31 was performed by isotype specific biotinylated goat anti-mouse $\mathrm{Ig}$ and subsequently by streptavidin conjugated to alkaline phosphatase, providing a blue reaction product using Fast Blue BB salt as a chromogen. Labelling of the adhesion antibodies was performed by isotype-specific goat anti-mouse antibody conjugated to peroxidase, using AEC as a reagent, giving a reddish brown reaction.

For each immunohistochemical staining, except for granzyme $B$ and vascular adhesions molecules, sections from two bronchial biopsies were quantified by computer-assisted image analysis at $\times 200$ (Qwin; Leica Microsystems Imaging Solutions Ltd, Cambridge, UK). Automated image analysis to quantify immunopositivity used the next algorithm: first the intensity of the positive area (cells) was appointed in each biopsy by the observer, followed by the intensity of the total area of the biopsy based on the red-green-blue colour model. After this, all images of the biopsy were analysed; excluded were epithelium, submucosal glands, airway smooth muscle and damaged tissue. Afterwards, the algorithm analysed the positive area and the measurable area of the biopsy leading to the percentage-positive area per biopsy. A positive area was $\geqslant 11.8 \mu \mathrm{m}^{2}$, to exclude false-positive areas. The minimal measurable area was $0.4 \mathrm{~mm}^{2}$. The mean percentage-positive area of two biopsies was used. Measurements were performed in a blinded way by one observer. Part of the biopsies were studied by both observers to determine inter-observer reproducibility, using BLAND and ALTMAN [23] analysis, showing good agreement between the two observers (mean difference $0.01 \pm 0.07$ ). Intra-observer reproducibility of the cellular parameters showed a mean difference ranging from 0.008 for EG2 to 0.09 for CD8 measurements. In addition, $95 \%$ of the differences of repeated measurements were between \pm 2 SD of the mean of differences and thus the reproducibility of inflammatory cells and markers was satisfactory in this respect.

Quantification of granzyme B was performed using morphometric measurements with a light microscope (Olympus BX40, Olympus, Japan) connected to a camera linked to a computerised image system (Research Assistant v4; RVC, Soest, the Netherlands) to measure the total measurable area (excluding epithelium, submucosal glands, airway smooth muscle tissue and damaged tissue). The number of granzyme B-cells was counted in each biopsy using a light microscope, at $\times 200$, in a blinded manner by one observer. The mean of two bronchial biopsies was used to calculate the number of positive cells per $\mathrm{mm}^{-2}$.

The vascular adhesion molecules were counted using a light microscope at $\times 400$. All vessels in one section were scored positive or negative for immunopositivity for an adhesion molecule and expressed as a percentage of the total number CD31 positive vessels. A minimum of 20 vessels were counted.

\section{Data analysis}

Values of $\mathrm{p}<0.05$ were considered statistically significant. Clinical data were expressed in means $\pm S D$, inflammatory variables were expressed in medians (minimum-maximum). Differences between smokers with COPD, smokers with chronic bronchitis and asymptomatic smokers at baseline were analysed using the Kruskall-Wallis test, a nonparametric equivalent to one-way ANOVA. When the Kruskall-Wallis test was significant the Mann-Whitney U-test was used to analyse the observed differences between the three groups. In the group of subjects who successfully managed to quit smoking, differences in sputum inflammation before and after 2, 6 and 12 months, smoking cessation were analysed using the Friedman's nonparametric two-way ANOVA, a nonparametric test to investigate multiple paired time points. If the Friedman test was significant, the Wilcoxon signed-rank test was used to define which time-points were different. Differences in airway inflammation in bronchial biopsies before and after 12 months smoking cessation were analysed using the Wilcoxon signedrank test. Since the authors wanted to compare airway inflammation in sputum and bronchial biopsies, the differences in sputum airway inflammation before and after 12 months smoking cessation were also analysed separately using the Wilcoxon-signed rank test. The Mann-Whitney U-test was used to compare baseline characteristics between the group of patients who quit smoking for $1 \mathrm{yr}$ and the group of patients who did not. 


\section{RESULTS}

\section{Patient characteristics}

A total of 28 smokers with COPD (13 mild, eight moderate and seven severe), 10 smokers with chronic bronchitis and normal lung function and 25 asymptomatic smokers with normal lung function, were included in the 1-yr smoking cessation programme. A total of 12 COPD patients (six mild, four moderate and two severe), four smokers with chronic bronchitis and 16 asymptomatic smokers successfully quit smoking for 1 yr. All urinary cotinine levels confirmed smoking cessation at 2, 6 and 12 months. None of the participants used nicotine replacements. Patient characteristics are presented in table 1.

Successful quitters with COPD had slightly lower percentage of sputum lymphocytes at baseline and a higher number of granzyme $\mathrm{B}+$ cells and higher percentage of ICAM-positive vessels than nonquitters with COPD ( 0.7 versus $1.1,0.18$ versus 0 , and 86 versus $70 \%$, respectively). The asymptomatic smokers who successfully quit were younger and the percentage of eosinophils in sputum was higher at baseline (49 versus 52 yrs and 1.1 versus $0.4 \%$, respectively) than in the asymptomatic nonquitters. The effects of smoking cessation on airway inflammation in smokers with chronic bronchitis could not be evaluated since only four smokers successfully quit smoking for a 1-yr period.

At baseline, COPD patients were slightly older, had more pack-yrs smoking and lower lung function than asymptomatic smokers with normal lung function (table 1). Sputum volume, total cells, percentage of sputum neutrophils and sputum IL-8 levels in COPD were significantly higher than in asymptomatic smokers (tables 2 and 3). Inflammatory markers in bronchial biopsies did not differ between the two groups at baseline (table 4). COPD patients had less P-selectin positive vessels than asymptomatic smokers (table 4 ).

\section{Effect of smoking cessation on lung function}

FEV1 post-bronchodilator (\% predicted) improved slightly after a 1-yr smoking cessation in COPD. No changes were found in FEV1/FVC post-bronchodilator (\%), RV/TLC, TL,CO or sGaw (table 1). Only TL,CO improved significantly after a 1 -yr smoking cessation in asymptomatic quitters (table 1).

\section{Effect of smoking cessation on airway inflammation in sputum}

Part of these data have been presented in a previous article in which the effect of smoking cessation on airway hyperresponsiveness is described in relation to sputum inflammation in smokers with COPD [21].

All 12 quitters with COPD, and 15 of the 16 asymptomatic quitters, produced both at baseline and at 2,6 and 12 months after smoking cessation sufficient sputum of good quality (tables 2 and 3).

In COPD, cell concentration, number of neutrophils, number of lymphocytes, IL-8 and ECP levels in sputum increased significantly after 12 months of smoking cessation (table 2, fig. 1). The percentages of eosinophils and macrophages tended to decrease after 12 months smoking cessation $(p=0.06$ and 0.08 , respectively).

\section{TABLE 1 Patient characteristics}

\begin{tabular}{|c|c|c|c|c|c|c|c|}
\hline & \multicolumn{3}{|c|}{ Totally included in SC programme } & \multicolumn{4}{|c|}{ Successful quitters } \\
\hline & \multirow[b]{2}{*}{ COPD } & \multirow[b]{2}{*}{$\begin{array}{c}\text { Smokers with } \\
\text { chronic bronchitis }\end{array}$} & \multirow[b]{2}{*}{$\begin{array}{l}\text { Asymptomatic } \\
\text { smokers }\end{array}$} & \multicolumn{2}{|c|}{ COPD } & \multicolumn{2}{|c|}{ Asymptomatic smokers } \\
\hline & & & & Baseline & SC 12 months & Baseline & SC 12 months \\
\hline Subjects $n$ & 28 & 10 & 25 & 12 & 12 & 16 & 16 \\
\hline Age yrs & $55 \pm 5.8$ & $52 \pm 4.6^{\#}$ & $50 \pm 3.7^{\bullet \#}$ & $56 \pm 5.7$ & & $49 \pm 3.2^{\#}$ & \\
\hline \multicolumn{8}{|l|}{ Sex } \\
\hline Male & 16 & 4 & 11 & 7 & 7 & 8 & 8 \\
\hline Female & 12 & 6 & 14 & 5 & 5 & 8 & 8 \\
\hline Smoking pack-yrs & $37 \pm 12$ & $32 \pm 13$ & $25 \pm 7.5^{\bullet}, \#$ & $35 \pm 14$ & & $24 \pm 7.2^{\#}$ & \\
\hline Cigarettes n. day ${ }^{-1}$ & $22 \pm 8$ & $23 \pm 7$ & $21 \pm 5$ & $21 \pm 9$ & & $21.5 \pm 5$ & \\
\hline FEV 1 post-BD \% pred & $71 \pm 21$ & $103 \pm 15^{\#}$ & $109.5 \pm 9.9^{\bullet, \# ~}$ & $74 \pm 16.8$ & $77 \pm 16.7^{+}$ & $111 \pm 8.8^{\#}$ & $108 \pm 12.5^{\S}$ \\
\hline FEV $1 /$ FVC post-BD \% & $59.6 \pm 10$ & $79 \pm 5^{\#}$ & $80 \pm 4.4^{\bullet}, \#$ & $61 \pm 11$ & $59 \pm 14$ & $80 \pm 4.9^{\#}$ & $81 \pm 5.9$ \\
\hline$T L, \operatorname{COsB} \mathrm{mmoL} \cdot \mathrm{min}^{-1} \cdot \mathrm{kPa}^{-1}$ & $6.9 \pm 2$ & $8.7 \pm 1.8^{\#}$ & $8.6 \pm 2^{\bullet, \#}$ & $7.5 \pm 2$ & $8.2 \pm 1.5$ & $8.9 \pm 1.9$ & $9.4 \pm 2^{+}$ \\
\hline RV/TLC \% & $44 \pm 11$ & $33 \pm 6^{\#}$ & $31 \pm 5^{\bullet}$ & $43 \pm 10$ & $42 \pm 7$ & $31 \pm 5$ & $30 \pm 6$ \\
\hline $\mathrm{Pa}, \mathrm{O}_{2} \mathrm{kPa}$ & $10.1 \pm 1.1$ & $11.0 \pm 1.2^{\#}$ & $11.2 \pm 1.2^{\bullet, \#}$ & $10.1 \pm 1.1$ & & $11.2 \pm 1.3^{\#}$ & \\
\hline sGaw $1 / k P a \cdot s^{-1}$ & $0.7 \pm 0.4$ & $1.4 \pm 0.6^{\#}$ & $1.8 \pm 0.7^{\bullet} \#$ & $0.7 \pm 0.3$ & $0.6 \pm 0.2$ & $1.9 \pm 0.8^{\#}$ & $1.6 \pm 0.4$ \\
\hline
\end{tabular}


TABLE 2 The effects of 2, 6 and 12 months' smoking cessation (SC) on sputum inflammation in chronic obstructive pulmonary disease (COPD)

Sputum

COPD quitters

\begin{tabular}{|c|c|c|c|c|}
\hline & \multirow[t]{2}{*}{ Baseline } & \multicolumn{3}{|c|}{ SC months } \\
\hline & & 2 & 6 & 12 \\
\hline Cell conc $\cdot 10^{6} \cdot \mathrm{mL}^{-1}$ & $1.3(0.48-9.62)$ & $3.4(0.03-13.87)$ & $2.8(0.21-11.6)$ & $6.3(0.4-12.29)^{\# .9}$ \\
\hline Volume sputum mL & $4.9(1.2-14.3)^{+}$ & $2.9(0.9-21.6)$ & $3.2(1.6-23.0)$ & $3.0(0.8-12.9)$ \\
\hline Total cells $10^{6}$ & $6.5(2.6-54.5)^{+}$ & $9.2(0.6-53.1)$ & $10.6(1.7-46.1)$ & $11.3(1.4-92.1)$ \\
\hline \multicolumn{5}{|l|}{ Eosinophils } \\
\hline $10^{6} \cdot \mathrm{mL}^{-1}$ & $0.03(0.003-0.1)$ & $0.01(0-0.1)$ & $0.01(0-0.2)$ & $0.01(0-0.14)$ \\
\hline$\%$ & $1.5(0.3-4.0)$ & $0.6(0-2.6)$ & $0.5(0-2.6)$ & $0.2(0-3.6)$ \\
\hline \multicolumn{5}{|l|}{ Neutrophils } \\
\hline $10^{6} \cdot \mathrm{mL}^{-1}$ & $0.77(0.24-7.6)$ & $2.97(0.02-9.1)$ & $1.22(0.2-8.9)$ & $4.56(0.1-11.0)^{\# .9}$ \\
\hline$\%$ & $73.2(45-86)^{+}$ & $84.5(38-97)$ & 68.1 (35.5-93) & 78.6 (31.6-89.8) \\
\hline \multicolumn{5}{|l|}{ Lymphocytes } \\
\hline $10^{6} \cdot \mathrm{mL}^{-1}$ & $0.01(0-0.08)$ & $0.008(0-0.1)$ & $0.04(0.005-0.2)$ & $0.05(0.005-0.2)^{\#}$ \\
\hline$\%$ & $0.70(0.10-1.10)$ & $0.8(0.1-1.3)$ & $1.2(0.5-2.3)^{\#}$ & $1.1(0.1-3.0)^{\S}$ \\
\hline \multicolumn{5}{|l|}{ Epithelial cells } \\
\hline $10^{6} \cdot \mathrm{mL}^{-1}$ & $0.01(0-0.70)$ & $0(0-0.08)$ & $0.04(0-0.8)^{\#}$ & $0.04(0-0.1)^{\xi, 9}$ \\
\hline$\%$ & $0.40(0-2.10)$ & $0.1(0-0.8)$ & $0.7(0-13.3)$ & $0.55(0-6)$ \\
\hline IL-8 $\mathbf{n g} \cdot \mathrm{mL}^{-1}$ & $18.90(0.64-60.60)^{+}$ & $34.1(0.97-1028)$ & $29.4(1.8-208)$ & $42.3(1.7-304)^{\#, 9}$ \\
\hline $\mathrm{ECP} \mu \mathrm{g} \cdot \mathrm{L}^{-1}$ & $157(32.4-804)$ & $193(27-9200)$ & $373(32-3780)$ & $780(27-3440)^{\#, \cdot}$ \\
\hline
\end{tabular}

Data are presented as median (range). Cell conc.: cell concentration; IL: interleukin; ECP: eosinophilic cationic protein. ${ }^{\#}: \mathrm{p}<0.05$ versus baseline; ${ }^{\bullet}$ : difference in change after 1 -yr smoking cessation between COPD and asymptomatic smokers with normal lung function $(\Delta){ }^{*}: p<0.05$ baseline difference between asymptomatic smokers and COPD; ${ }^{\text {s. }}$ p $<0.05$ Friedman test, difference between baseline, 2, 6 and 12 months' smoking cessation. $n=12$

In asymptomatic quitters, number and percentage of macrophages, percentage eosinophils and IL-8 levels in sputum decreased significantly after a 12-month smoking cessation (table 3, fig. 1). The percentage of neutrophils increased significantly in asymptomatic smokers at 6 and 12 months after smoking cessation was introduced, whereas the number of neutrophils did not (table 3).

The response to smoking cessation was significantly different between the two groups for cell concentration, the number of neutrophils, macrophages and epithelial cells and, IL-8 and ECP levels in sputum (table 2, 3 and fig. 2).

\section{Effect of smoking cessation on airway inflammation in bronchial biopsies}

Data on bronchial biopsies are presented in table 4 and figure 3. Biopsies of one COPD patient and of two asymptomatic smokers were of insufficient quality and therefore excluded from analyses. In COPD, none of the inflammatory cell markers and vascular adhesion molecules showed a significant change after ceasing to smoke for a 12-month period (table 4 ).

In asymptomatic quitters, mast cells (tryptase+cells) decreased significantly, whereas B-cells (CD20) increased significantly at
12 months smoking cessation (table 4 , fig. 3). The CD3+ cells tended to increase after smoking cessation $(p=0.09)$. The response to smoking cessation was significantly different between the two groups for mast cells.

The current authors also re-categorised the COPD patients according to the COPD criteria of the Global Initiative for Chronic Obstructive Lung Disease [24], which did not change the results (data not shown).

\section{DISCUSSION}

To the best of the authors' knowledge, this is the first longitudinal study investigating the effect of smoking cessation on airway inflammation in smokers with COPD. The present study shows that patients with COPD and asymptomatic smokers with normal lung function respond differently to smoking cessation with respect to inflammation in sputum and bronchial biopsies. In smokers with COPD, cell concentration, neutrophils, lymphocytes, IL-8 and ECP levels increased significantly in sputum after a 1-yr smoking cessation period, and inflammation did not change in bronchial biopsies. In contrast, inflammatory markers did not significantly change or decrease in sputum (macrophages, eosinophils, IL-8) of asymptomatic smokers with normal lung function. In 
TABLE 3 Effects of 2, 6 and 12 months' smoking cessation (SC) on sputum inflammation in asymptomatic smokers

Sputum

Asymptomatic quitters

\begin{tabular}{|c|c|c|c|c|}
\hline & & & & \\
\hline & Baseline & 2 & 6 & 12 \\
\hline Cell conc $\cdot 10^{6} \cdot \mathrm{mL}^{-1}$ & $1.76(0.3-4.59)$ & $1.86(0.39-4.50)$ & $1.33(0.31-6.02)$ & $1.34(0.39-14.65)^{\natural}$ \\
\hline Volume sputum $\mathrm{mL}$ & $2.1(1.0-10.8)^{+}$ & $2.8(0.2-12.8)$ & $3.0(0.2-16.4)$ & $3.1(0.4-18.1)$ \\
\hline Total cells $10^{6}$ & $3.6(0.3-22.9)^{+}$ & $6.1(0.1-26.48)$ & $4.6(0.1-11.52)$ & $3.9(0.2-26.8)$ \\
\hline \multicolumn{5}{|l|}{ Eosinophils } \\
\hline $10^{6} \cdot \mathrm{mL}^{-1}$ & $0.01(0-0.24)$ & $0.003(0-0.2)$ & $0.003(0-1.2)$ & $0.001(0-0.1)^{\S}$ \\
\hline$\%$ & $1.1(0-12.6)$ & $0.3(0-23)$ & $0.2(0-46.8)$ & $0.05(0-4.3)^{\#, \S}$ \\
\hline \multicolumn{5}{|l|}{ Neutrophils } \\
\hline $10^{6} \cdot \mathrm{mL}^{-1}$ & $0.67(0.18-2.9)$ & $1.17(0.27-3.1)$ & $0.81(0.21-3.1)$ & $0.90(0.33-9.1)^{\pi}$ \\
\hline$\%$ & $60.1(31.5-77)^{+}$ & $58.1(40.8-87)$ & $62.1(42.8-93.6)^{\#}$ & $80.1(42.8-91.3)^{\#, \$}$ \\
\hline \multicolumn{5}{|l|}{ Macrophages } \\
\hline \multicolumn{5}{|l|}{ Lymphocytes } \\
\hline $10^{6} \cdot \mathrm{mL}^{-1}$ & $0.01(0.001-0.16)$ & $0.01(0-0.07)$ & $0.007(0-0.03)^{\#}$ & $0.01(0-0.26)$ \\
\hline$\%$ & $0.8(0.3-3.8)$ & $0.8(0-2.3)$ & $0.8(0-2)$ & $1.0(0-3.8)$ \\
\hline \multicolumn{5}{|l|}{ Epithelial cells } \\
\hline $10^{6} \cdot \mathrm{mL}^{-1}$ & $0.02(0-0.06)$ & $0.01(0-0.08)$ & $0.01(0-1.1)$ & $0.01(0-0.38)^{\bullet}$ \\
\hline$\%$ & $1.1(0-6.6)$ & $0.5(0-5)$ & $0.6(0-41.8)$ & $1(0-3.6)$ \\
\hline $\mathrm{IL}-8 \mathrm{ng} \cdot \mathrm{mL}^{-1}$ & $5.8(1.8-25)^{+}$ & $5.0(0.2-16.5)$ & $3.4(0.2-32.1)$ & $3.1(0-94.5)^{\#, 9,5}$ \\
\hline $\mathrm{ECP} \mu \mathrm{g} \cdot \mathrm{L}^{-1}$ & $73.4(24.8-1282)$ & $101(11.5-580)$ & $96.8(22-1080)$ & $80.6(9.4-2340)^{\pi}$ \\
\hline
\end{tabular}

Data are presented as median (range). Cell conc.: cell concentration; IL: interleukin; ECP: eosinophilic cationic protein. ${ }^{\#}: \mathrm{p}<0.05$ versus baseline; ${ }^{\natural}$ : difference in change after 1-yr smoking cessation between COPD and asymptomatic smokers with normal lung function $(\Delta) ;^{+}: p<0.05$ baseline difference between asymptomatic smokers and COPD; ${ }^{\text {s: }} \mathrm{p}<0.05$ Friedman test, difference between baseline, 2, 6 and 12 months' smoking cessation. $n=16$.

bronchial biopsies, mast cells decreased significantly, whereas B-cells increased after smoking cessation. Together, the results suggest a perpetuation of inflammation after smoking cessation in COPD versus a reduction in some aspects of airway inflammation in asymptomatic smokers with normal lung function.

It is important to notice that airway inflammation in sputum persisted and even increased after smoking cessation in COPD patients in this study. Cell concentration, neutrophils and lymphocyte cell numbers, as well as IL-8 and ECP levels, increased significantly after 12 months smoking cessation, indicating that the current findings are not just spurious observations. Cross-sectional studies so far have not shown any differences in inflammatory cells in sputum between smokers and ex-smokers with COPD [6-8]. However, the time of smoking cessation varied between individuals in all studies so far, which may have obscured the effects found in the current prospective study. The results of previous studies on IL-8 levels in sputum are inconsistent: one study showed higher IL-8 levels in ex-smokers than in smokers [7], in agreement with the finding in the present study. Others did not find any differences [6, 8], whilst the use of inhaled corticosteroids by some subjects may have masked the effects of smoking cessation. This contrasts with the present study in which all COPD patients did not use inhaled and oral steroids for $\geqslant 6$ months prior to the study and only a short course of oral corticosteroids was used in case of an exacerbation during the study, although none of the participants took any in the month prior to any measurements. In the current study, ECP levels increased significantly after smoking cessation in COPD patients, whereas the number of eosinophils did not change. This may indicate that eosinophils are more activated after smoking cessation, whereas cell kinetics (recruitment) apparently do not change. The observation that ECP levels concordantly increased with neutrophils and IL-8 suggests a process of increased cell activation and selective migration.

An explanation for the observed increase in certain aspects of sputum inflammation in COPD may be that sputum is to be regarded as a waste bin, i.e. inflammatory cells are transported to the lumen and afterwards eliminated. It has been shown that not only apoptosis but also transepithelial migration may constitute an important pathway to eliminate cells from the airway walls [25]. Thus, an increase in sputum neutrophils may indicate a higher elimination rate, indicating an improvement of airway inflammation in lung tissue.

Another explanation for the increase in sputum inflammation may be reduced fluid production of the airways, and, thus, a higher concentration of inflammatory cells and mediators. As 
TABLE 4 Effects of 12 months' smoking cessation (SC) on inflammation in bronchial biopsies

\begin{tabular}{|c|c|c|c|c|}
\hline & \multicolumn{2}{|c|}{ COPD } & \multicolumn{2}{|c|}{ Asymptomatic smokers } \\
\hline & Baseline & $\begin{array}{c}\text { SC } \\
12 \text { months }\end{array}$ & Baseline & $\begin{array}{c}\text { SC } \\
12 \text { months }\end{array}$ \\
\hline Subjects n & 11 & 11 & 14 & 14 \\
\hline CD3 \% pos area & $0.7(0.2-8.9)$ & $1.2(0.02-6.1)$ & $0.8(0.2-2.4)$ & $1.6(0.2-5.2)^{\#}$ \\
\hline CD4 \% pos area & $0.04(0.02-0.36)$ & $0.05(0.01-0.26)$ & $0.04(0.02-0.2)$ & $0.05(0.004-0.4)$ \\
\hline CD8 \% pos area & $0.3(0.1-2.6)$ & $0.3(0.1-4.6)$ & $0.4(0.03-1.2)$ & $0.4(0.01-1.3)$ \\
\hline CD4/CD8 ratio & $0.1(0.02-1.2)$ & $0.2(0.05-0.6)$ & $0.2(0.02-0.9)$ & $0.2(0.03-1.6)$ \\
\hline CD20 \% pos area & $0.003(0-0.13)$ & $0.009(0-2.8)$ & $0.006(0-0.12)$ & $0.04(0.01-0.4)^{\bullet}$ \\
\hline CD68 \% pos area & $0.03(0-0.2)$ & $0.04(0-0.6)$ & $0.04(0-0.3)$ & $0.06(0.01-0.3)$ \\
\hline NP57 \% pos area & $0.03(0-0.1)$ & $0.05(0-0.7)$ & $0.03(0-0.4)$ & $0.02(0-0.5)$ \\
\hline EG2 \% pos area & $0.02(0-0.2)$ & $0.07(0-0.6)$ & $0.06(0-0.6)$ & $0.03(0-8.8)$ \\
\hline AA1 \% pos area & $0.2(0-0.8)$ & $0.2(0-0.9)$ & $0.3(0.01-1.2)$ & $0.1(0.01-0.8)^{\bullet++}$ \\
\hline Tia-1 \% pos area & $0(0-0.2)$ & $0.005(0-0.06)$ & $0.001(0-0.02)$ & $0.007(0-0.09)$ \\
\hline Granzyme B-cells $\cdot \mathbf{m m}^{-2}$ & $0.2(0-4.6)$ & $1.3(0-29)$ & $0(0-3.3)$ & $0.06(0-9.3)$ \\
\hline ICAM-1+vessels \% & $86(67-100)$ & $88(39-96)$ & $82(40-100)$ & 83 (22-92) \\
\hline vcAM+vessels \% & $0(0-0)$ & $0(0-3)$ & $0(0-5)$ & $0(0-27)$ \\
\hline P-selectin+vessels \% & $83(62-95)$ & $88(70-96)$ & $95(71-100)^{\S}$ & $92(80-100)$ \\
\hline E-selectin+vessels \% & $0(0-0)$ & $0(0-97)$ & $0(0-0)$ & $0(0-5)$ \\
\hline
\end{tabular}

Data are presented as median (range), unless otherwise stated. COPD: chronic obstructive pulmonary disease; \% pos area: percentage positive area; CD20: B-cells CD68: macrophages; NP57: neutrophils; EG2: eosinophils; AA1: mast cell tryptase; Tia-1: T-cell intracellular antigen-1; ICAM-1: intercellular adhesion molecule-1; VCAM: vascular cell adhesion molecule. ${ }^{\#}: p=0.09$ versus baseline; ${ }^{\bullet}: p<0.05$ versus baseline; ${ }^{+}: p<0.05$ difference in change in the 1 -yr smoking cessation between COPD patients and asymptomatic smokers with normal lung function $(\Delta) ;{ }^{s}: p<0.05$ versus COPD.

not all mediators showed a similar increase, the present authors find the latter explanation less likely.

No significant changes in inflammatory cells or vascular adhesion molecules were found in bronchial biopsies in COPD patients associated with smoking cessation. This suggests an ongoing inflammatory process in the airways, in agreement with cross-sectional studies in smokers and exsmokers with COPD $[3,4,9]$. The presented sputum data also suggests that inflammation continues and even increases after smoking cessation. This is in contrast to the current authors' previous findings that show that respiratory symptoms and airway hyperresponsiveness improve after smoking cessation $[21,26,27]$. It may be that other aspects of inflammation contribute to this rapid clinical improvement. A longer followup period may be needed to detect a reduction in airway inflammation, which may ultimately lead to less remodelling and the observed amelioration of lung function decline [26].

It is intriguing why airway inflammation is not resolved in COPD patients 1 yr after smoking cessation, and even increases in some aspects. One explanation is that an inflammatory trigger persists after smoking cessation, keeping a local inflammatory response intact. Possible candidates might be found in the bacterial colonisation in the lower airways of COPD patients, normally not found in healthy individuals [28, 29]. A recently suggested hypothesis is that COPD may have an autoimmune component, which contributes to the airway inflammation even after smoking cessation [30]. These auto-antibodies may be directed against antigens in tobacco or from endogenous auto-antigens as a result of smoking-induced inflammatory and oxidative lung injury [31, 32].
The increase in certain aspects of airway inflammation is difficult to explain. It may be due to the recovery of the proinflammatory capacity of epithelial and other resident cells after smoking cessation, or the disappearance of an antiinflammatory factor (e.g. carbon monoxide in cigarette smoke).

In a further attempt to explain the nonresolving inflammation in COPD, it is important to realise that cellular inflammation, apart from being a negative consequence of smoke exposure, is also an integrative part of a repair process. The current authors hypothesise that susceptible smokers who develop COPD do not sufficiently cope with the smoke-induced tissue damage, at least partly due to a hampered local repair reaction. One could anticipate that after smoking cessation the repair process in COPD patients restores the damage, which would also then involve inflammatory cells as part of the process. Thus, it may be that after smoking cessation, the increase in or maintenance of certain aspects of airway inflammation represents a beneficial, instead of a detrimental, factor.

In the asymptomatic smokers with normal lung function in the present study, many aspects of sputum airway inflammation were significantly reduced after smoking cessation. The number of macrophages, the percentage of eosinophils and IL-8 levels in sputum decreased significantly after 12 months smoking cessation, which is in agreement with the results of previous studies in BAL fluid and sputum [10-12, 14]. In addition, previous results have shown that in long-term exsmokers, macrophages in bronchial biopsies are lower than in ex-smokers with COPD [9]. This indicates that the cigarette smoke-induced increase in macrophages in asymptomatic smokers is reversible. Only the percentage of neutrophils 

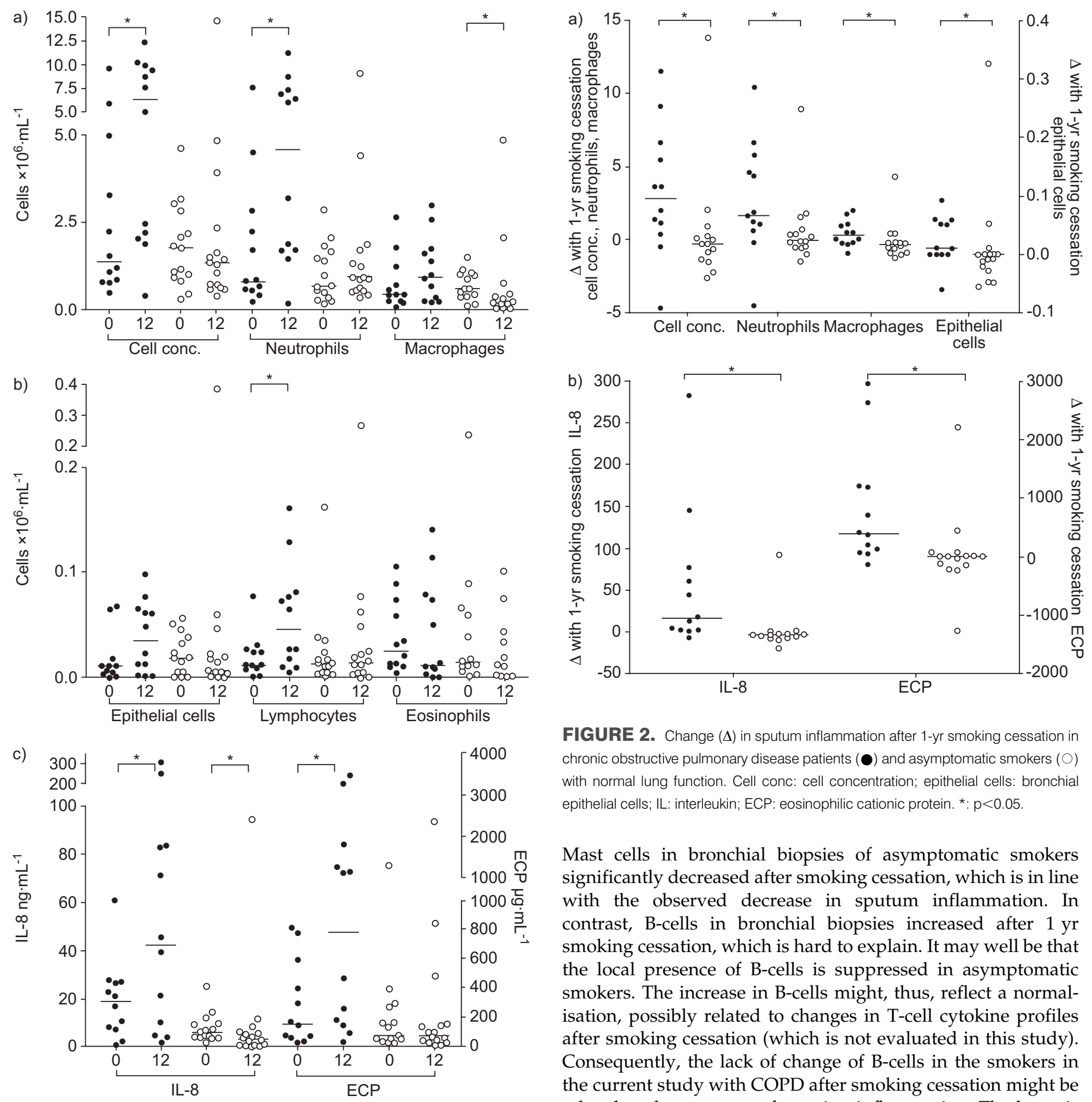

FIGURE 2. Change $(\Delta)$ in sputum inflammation after 1-yr smoking cessation in chronic obstructive pulmonary disease patients $(\bullet)$ and asymptomatic smokers $(O)$ with normal lung function. Cell conc: cell concentration; epithelial cells: bronchial epithelial cells; IL: interleukin; ECP: eosinophilic cationic protein. *: $p<0.05$.

Mast cells in bronchial biopsies of asymptomatic smokers significantly decreased after smoking cessation, which is in line with the observed decrease in sputum inflammation. In contrast, B-cells in bronchial biopsies increased after $1 \mathrm{yr}$ smoking cessation, which is hard to explain. It may well be that the local presence of B-cells is suppressed in asymptomatic smokers. The increase in B-cells might, thus, reflect a normalisation, possibly related to changes in T-cell cytokine profiles after smoking cessation (which is not evaluated in this study). Consequently, the lack of change of B-cells in the smokers in the current study with COPD after smoking cessation might be related to the presence of ongoing inflammation. The latter is consistent with previous studies, showing that the number of small airways containing B-cells is increased in ex-smokers with severe COPD [33].

Only a few significant changes in airway inflammation in bronchial biopsies were detected after smoking cessation, in contrast to sputum inflammation. The difference between the results of induced sputum and bronchial biopsies may be explained in several ways. Induced sputum collects accumulated mediators from both the central and peripheral airways [20]. It may be that airway inflammation changes after smoking cessation in the peripheral airways, and not in the 


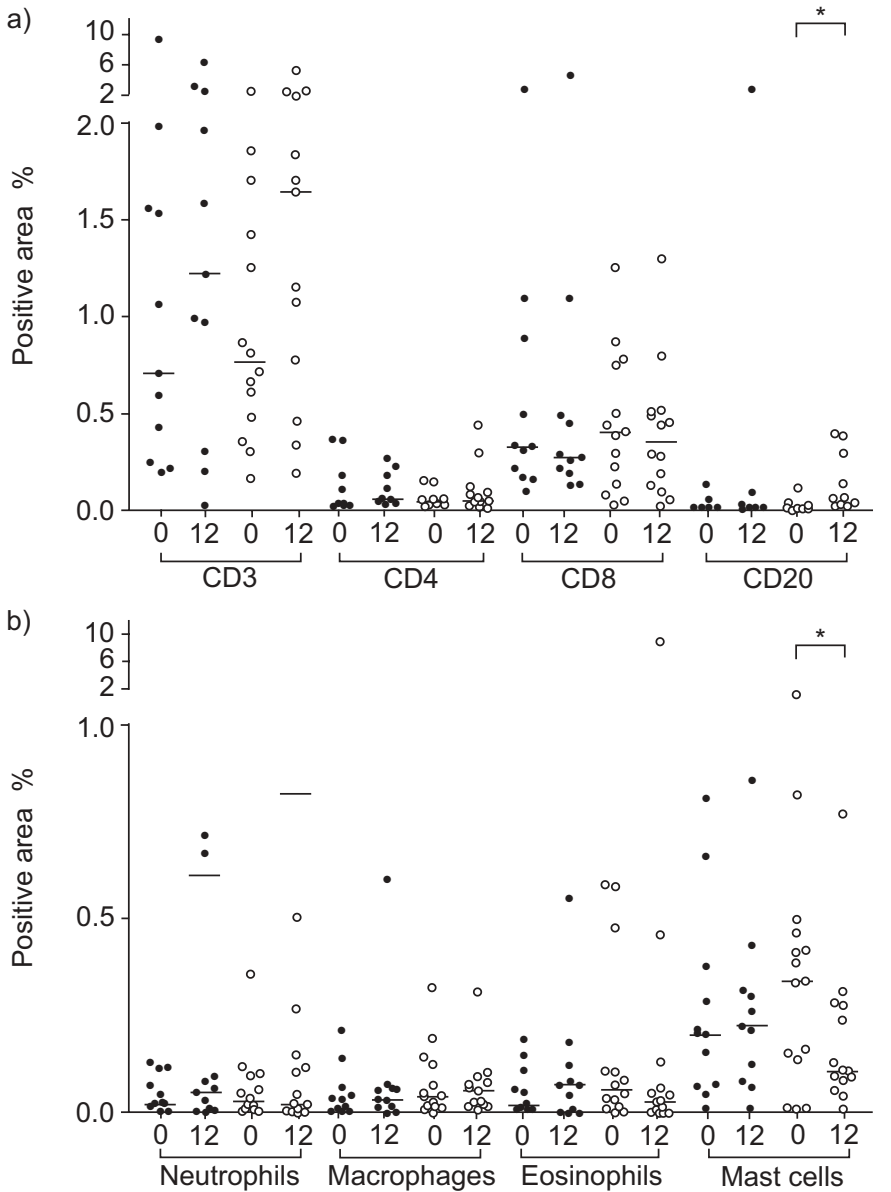

FIGURE 3. Effect of 1-yr smoking cessation on airway inflammation in bronchial biopsies in chronic obstructive pulmonary disease patients $(\bullet)$ and asymptomatic smokers $(O)$ with normal lung function. CD20: B-cells. *: $p<0.05$.

central airways. In addition, observations in sputum may detect traffic through the airway wall, better than in bronchial biopsies. The present authors investigated only the submucosa of the bronchial biopsies; other compartments (epithelium, glands, airway smooth muscle) might be more susceptible to smoking cessation.

At baseline, little differences in airway inflammation were found between smokers with COPD, asymptomatic smokers and smokers with chronic bronchitis. Sputum volume, total cells, percentage of sputum neutrophils and sputum IL-8 levels in COPD were significantly higher than in asymptomatic smokers. This is in line with previous studies that have shown that neutrophils and IL-8 levels in BAL and induced sputum are higher in smokers with COPD than without COPD [34-36]. In bronchial biopsies, the number of macrophages, neutrophils and CD8-positive cells are increased in smokers with COPD compared with smokers without COPD, especially in more severe COPD patients $[37,38]$. One of the reasons why the current study only found little differences in airway inflammation between smokers with COPD and asymptomatic smokers is that mild COPD patients were included. Another reason is that current smoking may have affected the results.
The overall success rate of the present smoking cessation programme was $52 \%$ after $1 \mathrm{yr}$. This rather high success rate is possibly due to a combination of a group-orientated smoking cessation programme, together with the research programme. This resulted in many contacts, either as in a group and or individually, which was appreciated and helped subjects to sustain smoking cessation. Next to this, participants received much information about their health status, which further encouraged them to quit. This approach is discussed in more detail elsewhere [39].

Unfortunately, the effects of smoking cessation in the asymptomatic smokers and COPD patients in the present study could not be compared with observations in individuals who were unable to quit smoking, since the medical ethics committee decided it unethical to re-assess individuals who relapsed after a smoking cessation attempt. However, the authors feel certain that the data are due to changes in smoking cessation, since multiple sputum inductions were performed, which show consistent results.

In the current study, the effect of smoking cessation on airway inflammation was studied in a relatively low number of patients. Nevertheless, significant differences in effects of smoking cessation between smokers with COPD and asymptomatic smokers were detectable, especially in induced sputum. More delicate inflammatory changes may become obvious in follow-up studies including larger numbers of patients.

The composition of sputum may differ between older and younger healthy subjects, comparable to the published increase in the number of cells and neutrophils in BAL with age [40]. Since the COPD patients and asymptomatic smokers investigated were of almost similar age (56 versus 49 yrs), the authors feel the current data are not hampered by age differences.

In conclusion, smokers with chronic obstructive pulmonary disease and asymptomatic smokers with normal lung function respond differently to 1-yr smoking cessation with respect to the smoke-induced airway inflammation. Several aspects of airway inflammation decreased in asymptomatic smokers with normal lung function whereas it persisted, or even increased, in some aspects in smokers with chronic obstructive pulmonary disease. Most changes were seen in sputum; macrophages, eosinophils and interleukin-8 levels significantly decreased in asymptomatic smokers whereas neutrophils, lymphocytes, interleukin-8 and eosinophilic cationic protein levels in chronic obstructive pulmonary disease patients significantly increased. The present authors suggest that the observed persistent inflammation in chronic obstructive pulmonary disease may be, at least partly, related to repair of the smoke-induced tissue damage in the airways. It remains to be elucidated which part of the observed inflammatory findings are beneficial and which are harmful.

\section{ACKNOWLEDGEMENTS}

This project was funded by the Dutch Asthma Foundation (NAF 97.74). The authors would like to thank A.A. Smidt for her assistance with the bronchial biopsies. The authors also thank I. Steketee and I. Barta-Sloots for their help with the granzyme and the eosinophilic cationic protein measurements. 


\section{REFERENCES}

1 Murray CJ, Lopez AD. Alternative projections of mortality and disability by cause 1990-2020: Global Burden of Disease Study. Lancet 1997; 349: 1498-1504.

2 Willemse BWM, Postma DS, Timens W, ten Hacken NHT. The impact of smoking cessation on respiratory symptoms, lung function, airway hyperresponsiveness and inflammation. Eur Respir J 2004; 23: 464-476.

3 Turato G, Di Stefano A, Maestrelli P, et al. Effect of smoking cessation on airway inflammation in chronic bronchitis. Am J Respir Crit Care Med 1995; 152: 1262-1267.

4 Pesci A, Rossi GA, Bertorelli G, Aufiero A, Zanon P, Olivieri D. Mast cells in the airway lumen and bronchial mucosa of patients with chronic bronchitis. Am J Respir Crit Care Med 1994; 149: 1311-1316.

5 de Boer WI, Sont JK, van Schadewijk A, Stolk J, van Krieken JH, Hiemstra PS. Monocyte chemoattractant protein 1, interleukin 8 , and chronic airways inflammation in COPD. J Pathol 2000; 190: 619-626.

6 Bhowmik A, Seemungal TA, Sapsford RJ, Wedzicha JA. Relation of sputum inflammatory markers to symptoms and lung function changes in COPD exacerbations. Thorax 2000; 55: 114-120.

7 Vernooy JH, Kucukaycan M, Jacobs JA, et al. Local and systemic inflammation in patients with chronic obstructive pulmonary disease: soluble tumor necrosis factor receptors are increased in sputum. Am J Respir Crit Care Med 2002; 166: 1218-1224.

8 Yamamoto C, Yoneda T, Yoshikawa M, et al. Airway inflammation in COPD assessed by sputum levels of interleukin-8. Chest 1997; 112: 505-510.

9 Rutgers SR, Postma DS, ten Hacken NH, et al. Ongoing airway inflammation in patients with COPD who do not currently smoke. Thorax 2000; 55: 12-18.

10 Skold CM, Hed J, Eklund A. Smoking cessation rapidly reduces cell recovery in bronchoalveolar lavage fluid, while alveolar macrophage fluorescence remains high. Chest 1992; 101: 989-995.

11 Skold CM, Forslid J, Eklund A, Hed J. Metabolic activity in human alveolar macrophages increases after cessation of smoking. Inflammation 1993; 17: 345-352.

12 Skold CM, Blaschke E, Eklund A. Transient increases in albumin and hyaluronan in bronchoalveolar lavage fluid after quitting smoking: possible signs of reparative mechanisms. Respir Med 1996; 90: 523-529.

13 Miller LG, Goldstein G, Murphy M, Ginns LC. Reversible alterations in immunoregulatory $\mathrm{T}$ cells in smoking. Analysis by monoclonal antibodies and flow cytometry. Chest 1982; 82: 526-529.

14 Swan GE, Hodgkin JE, Roby T, Mittman C, Jacobo N, Peters J. Reversibility of airways injury over a 12-month period following smoking cessation. Chest 1992; 101: 607-612.

15 Jensen EJ, Pedersen B, Schmidt E, Dahl R. Serum IgE in nonatopic smokers, nonsmokers, and recent exsmokers: relation to lung function, airway symptoms, and atopic predisposition. J Allergy Clin Immunol 1992; 90: 224-229.

16 Jensen EJ, Pedersen B, Frederiksen R, Dahl R. Prospective study on the effect of smoking and nicotine substitution on leucocyte blood counts and relation between blood leucocytes and lung function. Thorax 1998; 53: 784-789.
17 Siafakas NM, Vermeire P, Pride NB, et al. Optimal assessment and management of chronic obstructive pulmonary disease (COPD). The European Respiratory Society Task Force. Eur Respir J 1995; 8: 1398-1420.

18 Celli BR, Macnee W. Standards for the diagnosis and treatment of patients with COPD: a summary of the ATS/ ERS position paper. Eur Respir J 2004; 23: 932-946.

19 Quanjer PH, Tammeling GJ, Cotes JE, Pedersen OF, Peslin R, Yernault JC. Lung volumes and forced ventilatory flows. Eur Respir J 1993; Suppl. 16, 5-40.

20 Rutgers SR, Timens W, Kaufmann HF, van der Mark TW, Koeter GH, Postma DS. Comparison of induced sputum with bronchial wash, bronchoalveolar lavage and bronchial biopsies in COPD. Eur Respir J 2000; 15: 109-115.

21 Willemse BWM, ten Hacken NHT, Rutgers B, LesmanLeegte IGAT, Timens W, Postma DS. Smoking cessation improves direct and indirect airway hyperresponsiveness in COPD. Eur Respir J 2004; 24: 391-396.

22 Aleva RM, Kraan J, Smith M, ten Hacken NH, Postma DS, Timens W. Techniques in human airway inflammation: quantity and morphology of bronchial biopsy specimens taken by forceps of three sizes. Chest 1998; 113: 182-185.

23 Bland JM, Altman DG. Statistical methods for assessing agreement between two methods of clinical measurement. Lancet 1986; 1: 307-310.

24 Global initiative for Chronic Obstructive Lung Disease NIoH. Definitions chapter 1 in Global Initiative for Chronic Obstructive Lung Disease. GOLD 2003; 5-10.

25 Erjefalt JS, Uller L, Malm-Erjefalt M, Persson CG. Rapid and efficient clearance of airway tissue granulocytes through transepithelial migration. Thorax 2004; 59: 136-143.

26 Anthonisen NR, Connett JE, Murray RP. Smoking and lung function of lung health study participants after 11 years. Am J Respir Crit Care Med 2002; 166: 675-679.

27 Kanner RE, Connett JE, Williams DE, Buist AS. Effects of randomized assignment to a smoking cessation intervention and changes in smoking habits on respiratory symptoms in smokers with early chronic obstructive pulmonary disease: the Lung Health Study. Am J Med 1999; 106: 410-416.

28 Cabello H, Torres A, Celis R, et al. Bacterial colonization of distal airways in healthy subjects and chronic lung disease: a bronchoscopic study. Eur Respir J 1997; 10: 1137-1144.

29 Zalacain R, Sobradillo V, Amilibia J, et al. Predisposing factors to bacterial colonization in chronic obstructive pulmonary disease. Eur Respir J 1999; 13: 343-348.

30 Agusti A, Macnee W, Donaldson K, Cosio M. Hypothesis: does COPD have an autoimmune component? Thorax 2003; 58: 832-834.

31 Barnes PJ, Cosio MG. Characterization of T lymphocytes in chronic obstructive pulmonary disease. PLoS Med 2004; 1: e20.

32 Cosio MG. Autoimmunity, T-cells and STAT-4 in the pathogenesis of chronic obstructive pulmonary disease. Eur Respir J 2004; 24: 3-5.

33 Hogg JC, Chu F, Utokaparch S, et al. The nature of smallairway obstruction in chronic obstructive pulmonary disease. N Engl J Med 2004; 350: 2645-2653.

34 Keatings VM, Collins PD, Scott DM, Barnes PJ. Differences in interleukin-8 and tumor necrosis factor-alpha in 
induced sputum from patients with chronic obstructive pulmonary disease or asthma. Am J Respir Crit Care Med 1996; 153: 530-534.

35 Thompson AB, Daughton D, Robbins RA, Ghafouri MA, Oehlerking M, Rennard SI. Intraluminal airway inflammation in chronic bronchitis. Characterization and correlation with clinical parameters. Am Rev Respir Dis 1989; 140: 1527-1537.

36 Lacoste JY, Bousquet J, Chanez P, et al. Eosinophilic and neutrophilic inflammation in asthma, chronic bronchitis, and chronic obstructive pulmonary disease. J Allergy Clin Immunol 1993; 92: 537-548.

37 Lams BE, Sousa AR, Rees PJ, Lee TH. Subepithelial immunopathology of the large airways in smokers with and without chronic obstructive pulmonary disease. Eur Respir J 2000; 15: 512-516.

38 Di Stefano A, Capelli A, Lusuardi M, et al. Severity of airflow limitation is associated with severity of airway inflammation in smokers. Am J Respir Crit Care Med 1998; 158: 1277-1285.

39 Willemse B, Lesman-Leegte I, Timens W, Postma D, ten Hacken N. High quit rates of cigarette smoking both in subjects with and without COPD. Chest 2005; (In press).

40 Meyer KC, Ershler W, Rosenthal NS, Lu XG, Peterson K. Immune dysregulation in the aging human lung. Am J Respir Crit Care Med 1996; 153: 1072-1079. 